\title{
ASPEK BIOLOGIS ULATSUTERA (Bombyx mori L.) DARI DUA SUMBER BIBIT DI SULAWESI SELATAN
}

\author{
Biological Aspect of Silkworm (Bombyx Mori L.) from Two Seeds Resources in South Sulawesi
}

Sitti Nuraeni dan Beta Putranto

\begin{abstract}
The purpose of this research to compared the biological aspect of silkworm seeds with two resources of seeds in South Sulawesi are Perum Perhutani $\left(P_{1}\right)$ and China hybrid $\left(P_{2}\right)$. The result of this research can be information for user of the sericulture. The observation will be done the hatchability of eggs, resistance of larva, and the characteristic of the larval. The observation of the cocoon quality such as whole fresh cocoon weight, the cocoon without pupa weight, the presentation of shell cocoon, the presentation of abnormal cocoon, and the characteristic of the cocoon. The data was analyzed with using proportion different test and t-student test. The result of this research was showed that hatchability of kind eggs as not significant. The resistance of larva as the higher from $\mathrm{P}_{2}$ and presentation of abnormal cocoon was lower. So the cocoon without pupa was not significant with the seeds from $\mathrm{P}_{1}$, but the cocoon weight and size of cocoon are bigger than from $P_{2}$. Both larva motif and cocoon characteristic from $P_{1}$ and from China hybrid is significant, but larva stadia from $P_{2}$ was shorter than from $P_{1}$.
\end{abstract}

Key words : Biological aspect, silkworm (Bombyx mori), seeds resources

\section{PENDAHULUAN}

Ulatsutera (Bombyx mori L.) merupakan salah satu jenis serangga dari Ordo Lepidoptera. Serangga ini bernilai ekonomis sangat tinggi bagi manusia, karena di akhir fase larvanya dapat membentuk kokon dari serat sutera. Sutera ini merupakan bahan baku industri tekstil, benang bedah, parasut dan berbagai keperluan lainnya. Keistimewaan serat sutera sampai saat ini belum bisa terkalahkan oleh serat sutera buatan.

Kebutuhan akan sutera dari tahun ke tahun belum mampu memenuhi target setiap tahunnya. Sulawesi Selatan merupakan penghasil sutera terbesar untuk memenuhi kebutuhan nasional. Data produksi sutra Sulawesi Selatan sendiri dalam kurun waktu satu dasa warsa saja mengalami penurunan. Jurnal Sulsel (2004), pada tahun 1993, produksi sutera mencapai 120 ton dan terus mengalami penurunan, hingga pada tahun 2003 hanya mencapai 60 ton. Banyak faktor yang mempengaruhi penurunan produksi sutera di Sulawesi Selatan antara lain permasalahan bibit atau telur ulat yang digunakan. Bibit ulatsutera yang beredar saat ini adalah hasil persilangan dari induk yang berasal dari daerah sub tropis (bivoltine), ternyata belum bisa beradaptasi dengan baik dalam kondisi daerah tropis seperti Indonesia (Nuraeni, 1993).

Bibit yang resmi beredar saat ini adalah yang diproduksi oleh Perum Perhutani sejak tahun 1980an. Perkembangan mutu bibit ini mengalami pasang surut yang mendorong munculnya produsen bibit lainnya yang belum bisa direkomendasikan seperti produsen bibit baru yang didatangkan dari negara China. Jenis bibit ini baik aspek biologis ulatnya ataupun kualitas seratnya belum ada datanya secara lengkap. Dari uraian tersebut, maka dianggap perlu untuk melakukan penelitian dari bibit yang baru direkomendasikan dan bibit yang telah lama direkomendasikan dari Perum Perhutani sebagai pembanding.

\section{BAHAN DAN METODE}

\section{Waktu dan Tempat Penelitian}

Penelitian ini dilaksanakan di Desa Sering Kecamatan Donri-Donri Kabupaten Soppeng. Penelitian ini berlangsung selama 4 bulan (MeiAgustus 2007), yang diawali dengan persiapan, survei dan pelaksanaan penelitian serta penyusunan laporan. 
Table 1. The Shootlest, chopped size and amount of mulberry leaves supplied for larval of silkworm.

\begin{tabular}{|c|l|c|c|}
\hline Instar & Duduk daun dari pucuk sampai ke- & Ukuran rajangan daun (cm) & Banyaknya daun (kg/boks) \\
\hline I & Daun IV-V & $0,5-1$ & 2 \\
II & Daun VI-VII & $1,5-2,0$ & 5 \\
III & Daun VIII-IX & $3,0-5,0$ & 30 \\
IV & Semua daun, utuh dengan rantingnya & - & 100 \\
V & Semua daun, utuh dengan rantingnya & - & 700 \\
\hline Jumlah & & & $837 \mathrm{~kg} / \mathrm{boks}$ \\
\hline & & & \\
\hline
\end{tabular}

\section{Prosedur Penelitian}

\section{Pemeliharaan Ulat}

Sebelum pemeliharaan, makanan pertama pada instar pertama (hakitate) terlebih dahulu dilakukan desinfeksi tubuh ulat dengan bubuk kaporit $5 \%$ dicampur $95 \%$ kapur yang ditaburkan sebanyak satu gram per $0,1 \mathrm{~m}^{2}$ untuk ulat instar I, ulat instar II sebanyak 2 gram dan ulat instar III sebanyak 3 gram. Desinfeksi tubuh ulat instar IV dan $\mathrm{V}$ dilakukan dengan menggunakan bubuk kaporit 10\% dicampur 90\% kapur. Banyaknya campuran yang ditaburkan adalah 50 sampai 60 gram setiap $\mathrm{m}^{2}$. Desinfeksi dilakukan setelah setiap kali ulat berganti kulit dan sebelum pemberian makan.

Pemberian makan (pakan) untuk ulat sutera berbeda untuk setiap instar, baik banyaknya maupun cara pemberiannya. Tabel 1 menjelaskan duduk daun yang dipetik, ukuran rajangan dan banyaknya daun yang diberikan pada setiap instar.

\section{Pengokonan Ulat}

Ulat akhir instar $V$ atau ulat yang telah matang memperlihatkan tanda-tanda sebagai berikut: nafsu makan ulat berkurang atau hilang sama sekali, tubuh kekuning-kuningan, dari bawah mulutnya ada organ yang mengeluarkan serat sutera dan ulat cenderung ke pinggir atau naik ke sisi sasag. Bila ulat telah memperlihatkan tandatanda seperti yang disebutkan, maka segera ulat dipindahkan ke tempat pengokonan.

\section{Panen dan Seleksi Kokon}

Panen kokon dilakukan setelah kokon berumur 6-7 hari, yaitu bila pupa telah berbentuk sempurna. Kokon segera dibersihkan dan diseleksi kokon yang bermutu baik. Kokon yang bermutu baik segera dipersiapkan untuk dipintal.

\section{Analisis Data}

Percobaan ini dilakukan dengan dua perlakuan yaitu bibit dari Perum Perhutani (P1) dan bibit Hibrid China (P2). Masing-masing perlakuan diulangi tiga kali. Hasil dari penelitian ini dianalsis dengan menggunakan uji-t. Adapun variabel yang diamati adalah :

1. Data tetas telur $(\%)$

$=$ Jumlah telur menetas $\times 100 \%$ Jumlah telur yang dibuahi

2. Daya bertahan ulat kecil (instar I-III )(\%) = Jumlah ulat instar III X 100\% Jumlah ulat awal instar IV

3. Daya bertahan ulat besar (instar IV-V) (\%) $=$ Jumlah ulat yang akan mengokon $\times 100 \%$ Jumlah ulat awal instar IV

4. Bobot kokon segar (gram)

5. Bobot kulit kokon (gram)

6. Persentase kulit kokon (\%)

$=$ Bobot kulit kokon X 100\% Bobot kokon segar

7. Persentase kokon cacat (\%)

$=$ Jumlah kokon cacat $\times 100 \%$ Jumlah ulat mengokon

8. Karakteristik ulat (larva) dan kokon dari kedua bibit ulatsutera.

a. Karakteristik ulat, meliputi: panjang ulat instar $V$, warna ulat dan tanda yang khas.

b. Karakteristik kokon, meliputi: bentuk, ukuran kokon dan kekerasan kokon

\section{HASIL DAN PEMBAHASAN}

Beberapa variabel yang diamati dalam percobaan ini merupakan sebagian penilaian untuk melihat daya tahan ulat dan kualitas kokonnya. Penilaian daya tahan ulat dapat dilihat pada variabel daya tetas telur, daya tahan ulat kecil (ulat instar I sampai III), daya tahan ulat besar (ulat instar IV sampai V). Sedangkan penilaian kualitas kokon dapat dilihat pada variabel berat kokon segar, berat kokon tanpa pupa, persentase kulit kokon, persentase kokon cacat, dan karakteristik kokon. Variabel lain yang turut menentukan produktivitas kokon adalah karakteristik ulat sutera dan perkembangan larva. 
Tabel 2. The survival percentage of abnormal larval and cocoon with difference proportion test.

\begin{tabular}{clrc}
\hline \multirow{2}{*}{ No } & \multicolumn{1}{c}{ Variabel } & Bibit P1 & Proporsi (\%) \\
\cline { 3 - 4 } & & $81,7 \mathrm{a}$ & $82,52^{\mathrm{a}}$ \\
\hline 1 & Daya Tetas Telur & $79,79 \mathrm{a}$ & $95,13^{\mathrm{b}}$ \\
2 & Daya Tahan Hidup Ulat Kecil & $68,33^{\mathrm{a}}$ & $88,67^{\mathrm{b}}$ \\
3 & Daya Tahan Hidup Ulat Besar & $8,78^{\mathrm{b}}$ & $4,13^{\mathrm{a}}$ \\
\hline
\end{tabular}

Remarks: The value in the same row followed by the same letter is not significant at $\alpha=5 \%$.

Hasil pengamatan yang diperoleh berdasarkan uji beda proporsi daya tetas telur, daya tahan ulat kecil, daya tahan ulat besar, dan persentase kokon cacat antara bibit Perum Perhutani $\left(\mathrm{P}_{1}\right)$ dan bibit Hibrid China $\left(\mathrm{P}_{2}\right)$ pada suhu pagi hari $25-$ $30^{\circ} \mathrm{C}$, suhu siang hari $28-33^{\circ} \mathrm{C}$, dan kelembaban udara 55-79\%, dapat dilihat pada Tabel 2 .

Hasil pengamatan yang diperoleh berdasarkan uji beda rata-rata terhadap berat kokon segar, berat kokon tanpa pupa, persentase kulit kokon, panjang kokon, dan lebar kokon antara bibit $P_{1}$ dan $P_{2}$ pada suhu pagi hari $25-30^{\circ} \mathrm{C}$, suhu siang hari $28-33^{\circ} \mathrm{C}$, dan kelembaban udara $55-79$ $\%$, dapat dilihat pada Tabel 3 .

\section{Daya Tetas Telur}

Hasil uji pada Tabel 3 menunjukkan adanya perbedaan yang tidak nyata pada taraf nyata $5 \%$ (dengan kata lain relatif sama) dari daya tetas telur antara bibit $P_{1}$ dan bibit $P_{2}$, di mana persentase daya tetas telur antara kedua bibit tersebut adalah sebesar $82,52 \%$ dan $81,70 \%$.

Hasil penelitian daya tetas telur bibit $\mathrm{P}_{2}$ yang dilakukan lebih rendah jika dibandingkan dengan hasil penelitian yang dilakukan oleh BPA (1992) untuk induk $P_{2}$, yaitu sebesar $96,05 \%$. Demikian pula daya tetas telur bibit $P_{1}$ yang dihasilkan lebih rendah jika dibandingkan dengan hasil penelitian hibrid yang sama yaitu 87,53-96,05 \% (Suriyani, 1993). Standar daya tetas telur untuk bibit komersil sebaiknya di atas $90 \%$ (Tabel 3).
Menurut Atmosoedarjo et al. (2000), untuk mendapatkan persentase penetasan yang tinggi diperlukan penyimpanan dan penanganan telur yang baik, di samping penetasan buatan dan inkubasi. Untuk persiapan penetasan dibutuhkan suhu $25^{\circ} \mathrm{C}$, kelembaban udara $80 \%$, peredaran udara $0,3 \mathrm{~m} / \mathrm{s}$, pengaturan cahaya terang selama 17 sampai 18 jam/hari dan kondisi gelap selama 6 sampai 7 jam/hari dan lamanya masa inkubasi telur selama 10 hari (Katsumata, 1964). Rendahnya daya tetas telur bibt $P_{2}$ diduga disebabkan oleh proses distribusi yang cukup jauh dan lama, di mana bibit $\mathrm{P}_{2}$ masih diimpor langsung dari negara China sehingga syarat-syarat penetasan telur selama masa inkubasi tersebut sulit dipenuhi.

\section{Daya Tahan Hidup Ulat Kecil}

Hasil uji pada Tabel 3 menunjukkan adanya perbedaan yang nyata untuk taraf nyata $5 \%$ dari daya tahan ulat kecil antara bibit $P_{1}$ dan bibit $P_{2}$, di mana persentase daya tahan hidup ulat kecil dari bibit $\mathrm{P}_{2}$ sebesar $95,13 \%$ dan bibit $\mathrm{P} 1$ sebesar $79,79 \%$. Hasil penelitian daya tahan hidup ulat kecil dari bibit $P_{2}$ yang dilakukan lebih rendah jika dibandingkan dengan hasil penelitian yang dilakukan oleh BPA (1992) untuk induk China, yaitu sebesar $98,70 \%$. Demikian pula daya tahan hidup ulat kecil bibit hibrid yang dihasilkan lebih rendah jika dibandingkan dengan hasil penelitian hibrid yang sama, yaitu 94,11-97,50 \% (Suriyani, 1993).

Tabel 3. The quality of cocoon of $P_{1}$ and $P_{2}$ seeds.

\begin{tabular}{|c|c|c|c|c|c|c|c|}
\hline \multirow[t]{2}{*}{ No } & \multirow[t]{2}{*}{ Variabel } & \multicolumn{2}{|c|}{$\begin{array}{l}\text { Rata-rata hasil pengukuran } \\
\text { pada tiap perlakuan }\end{array}$} & \multirow[t]{2}{*}{$t_{h}$} & \multirow[t]{2}{*}{$\mathrm{db}$} & \multirow[t]{2}{*}{ Sig } & \multirow[t]{2}{*}{ Keterangan } \\
\hline & & Bibit $\mathrm{P}_{1}$ & Bibit $\mathrm{P}_{2}$ & & & & \\
\hline 1. & Berat Kokon Segar (g) & 1,53 & 1,44 & $-3,380$ & 178 & 0,010 & * \\
\hline 2. & Berat Kokon Tanpa Pupa (g) & 0,30 & 0,29 & $-1,430$ & 163 & 0,154 & tn \\
\hline 3. & Persentase Kulit Kokon (\%) & 19,91 & 20,72 & 1,842 & 151 & 0,067 & \# \\
\hline 4. & Panjang Kokon (mm) & 34,68 & 31,40 & $-7,699$ & 28 & 0,000 & ** \\
\hline 5. & Lebar Kokon (mm) & 19,53 & 16,47 & $-9,711$ & 28 & 0,000 & ** \\
\hline
\end{tabular}

Remarks: ${ }^{* *}=$ very significant at $\alpha=5 \%$

* $=$ significant at $\alpha=5 \%$

tn $=$ no significant at $\alpha=5 \%$

$\#=$ significant $\alpha=10 \%$ but not significant at $\alpha=5 \%$. 
Daya tahan hidup ulat sutera banyak dipengaruhi oleh faktor lingkungan terutama suhu dan kelembaban udara selama pemeliharaan. Menurut Krishnaswami (1973) dalam Samsiyah dan Kusumaputra (1979), suhu yang cocok untuk pertumbuhan ulat kecil adalah $24-28^{\circ} \mathrm{C}$ dan kelembaban udara $80-90 \%$. Sejalan dengan pernyataan tersebut maka suhu dan kelembaban selama pengamatan belum optimum disebabkan karena sulitnya mengendalikan faktor lingkungan pada ruang pemeliharaan.

\section{Daya Tahan Hidup Ulat Besar}

Hasil uji pada Tabel 2 menunjukkan adanya perbedaan yang nyata pada taraf nyata $5 \%$ dari daya tahan hidup ulat besar antara bibit $\mathrm{P}_{1}$ dan bibit $P_{2}$, di mana persentase daya tahan hidup ulat besar dari bibit $\mathrm{P}_{2}$ sebesar $88,67 \%$ dan bibit $\mathrm{P}_{1}$ sebesar $68,33 \%$.

Hasil penelitian daya tahan hidup ulat besar dari kedua bibit ulat yang dilakukan lebih rendah jika dibandingkan dengan hasil penelitian yang dilakukan oleh Higashi (1971), yaitu sebesar 96,07 $\%$. Standar untuk bibit komersil sebaiknya di atas $90 \%$ (Tabel 1).

Rendahnya persentase daya tahan hidup ulat besar disebabkan oleh beberapa faktor, di antaranya adalah faktor lingkungan yang sulit dikendalikan seperti keadaan cuaca yang berubahubah dan adanya serangan dari organisme perusak (semut, kadal, cecak, dan tikus).

\section{Persentase Kokon Cacat}

Hasil uji pada Tabel 3 menunjukkan adanya perbedaan yang nyata pada taraf nyata $5 \%$ dari persentase kokon cacat antara bibit $P_{1}$ dan bibit $P_{2}$, di mana persentase kokon cacat dari bibit $\mathrm{P}_{1}$ sebesar $8,78 \%$ dan bibit $\mathrm{P}_{2}$ sebesar $4,14 \%$. Perbedaan tingkat persentase kokon cacat antara bibit $P_{1}$ dan bibit $P_{2}$ disebabkan karena adanya pertumbuhan larva yang kurang sehat dari bibit $P_{1}$ seperti yang telah diuraikan pada penjelasan sebelumnya. Hal ini didukung dengan pendapat Kaomini dan Sampe (1988) dalam Nuraeni (1993) bahwa larva yang kurang sehat umumnya menghasilkan kokon yang kurang sempurna.

\section{Berat Kokon Segar}

Hasil uji pada Tabel 4 menunjukkan adanya perbedaan yang nyata pada taraf nyata $5 \%$ dari berat kokon segar antara bibit $\mathrm{P}_{1}$ dan bibit $\mathrm{P}_{2}$, di mana rata-rata berat kokon segar bibit $P_{1}$ sebesar $1,53 \mathrm{~g}$ dan bibit $P_{2}$ sebesar $1,44 \mathrm{~g}$. Hal ini menggambarkan bahwa bibit $P_{1}$ memiliki berat kokon segar yang lebih tinggi dibanding dari bibit $\mathrm{P}_{2}$.

Hasil penelitian berat kokon segar dari bibit $\mathrm{P}_{2}$ yang dilakukan lebih tinggi jika dibandingkan dengan hasil penelitian yang dilakukan oleh BPA (1992) untuk induk china, yaitu sebesar 0,95-1,24 g. Demikian pula hasil berat kokon segar bibit $P_{1}$ yang dilakukan lebih rendah jika dibandingkan dengan hasil penelitian hibrid yang sama, yaitu sebesar 1,64 g (Arif, 1994). Namun, hasil pengamatan berat kokon segar bibit $P_{1}$ yang dilakukan masih sesuai dengan standar berat kokon segar untuk bibit komersil (Tabel 1).

Adanya perbedaan berat kokon disebabkan oleh jenis atau ras ulat sutera yang diamati, di mana ulat bibit $\mathrm{P}_{1}$ memiliki ukuran tubuh yang relatif lebih besar dari bibit $P_{2}$. Hal tersebut sesuai dengan pendapat Katsumata (1964) bahwa jenis ulat sutera, jenis kelamin pupa dan cara pemeliharaan sangat berpengaruh terhadap bobot kokon segar yang dihasilkan.

\section{Berat Kokon Tanpa Pupa}

Hasil uji pada Tabel 4 menunjukkan adanya perbedaan yang tidak nyata pada taraf nyata $10 \%$ dari berat kokon tanpa pupa antara bibit $\mathrm{P}_{2}$ dan bibit $\mathrm{P}_{1}$, di mana rata-rata berat kokon tanpa pupa bibit $P_{2}$ sebesar $0,29 \mathrm{~g}$ dan bibit $P_{1}$ sebesar $0,30 \mathrm{~g}$. Hal ini menggambarkan bahwa kedua bibit tersebut memiliki kemampuan yang sama dalam hal menghasilkan serat sutera.

Hasil penelitian berat kokon tanpa pupa dari bibit $P_{2}$ yang dilakukan lebih tinggi jika dibandingkan dengan hasil penelitian yang dilakukan oleh BPA (1992) untuk induk China, yaitu sebesar $0,18-0,22 \mathrm{~g}$. Demikian pula hasil berat kokon tanpa pupa bibit $P_{1}$ yang dilakukan lebih rendah jika dibandingkan dengan hasil penelitian hibrid yang sama, yaitu sebesar $0,47 \mathrm{~g}$ (Arif, 1994). Namun, hasil penelitian berat kokon tanpa pupa bibit $P_{1}$ yang dilakukan masih sesuai dengan beberapa hasil penelitian hibrid yang sama dan standar berat kokon tanpa pupa untuk bibit komersil (Tabel 1).

Menurut Samsiyah dan Kusumaputra (1979), berat kokon tanpa pupa (berat kulit kokon) banyak dipengaruhi oleh ras ulat sutera yang dipelihara, 
jumlah mutu dan pakan yang diberikan, lingkungan pemeliharaan dan cara pemeliharaan ulat sutera.

\section{Persentase Kulit kokon}

Hasil uji pada Tabel 4 menunjukkan adanya perbedaan yang tidak nyata pada taraf nyata $5 \%$ tetapi berbeda nyata pada taraf nyata $10 \%$ dari persentase kulit kokon antara bibit $P_{2}$ dan bibit $P_{1}$, di mana persentase kulit kokon bibit $\mathrm{P}_{2}$ sebesar 20,72 \% dan bibit P1 sebesar 19,91\%.

Hasil penelitian persentase kulit kokon dari bibit $\mathrm{P}_{2}$ lebih tinggi jika dibandingkan dengan hasil penelitian yang dilakukan oleh BPA (1992) untuk induk China, yaitu sebesar 18,04-19,39\%. Demikian pula hasil persentase kulit kokon bibit P1 yang dilakukan lebih rendah jika dibandingkan dengan hasil penelitian hibrid yang sama, yaitu sebesar 28,99 \% (Arif, 1994). Namun, persentase kulit kokon bibit P1 dari pengamatan yang dilakukan masih sesuai dengan beberapa hasil penelitian yang sama dan standar persentase kulit kokon untuk bibit komersil (Tabel 1).

Adanya perbedaan tingkat persentase kulit kokon disebabkan oleh adanya perbedaan jenis atau ras ulat tersebut. Hal ini didukung oleh pernyataan Samsiyah dan Kusumaputra (1979) bahwa berat kokon tanpa pupa (berat kulit kokon) banyak dipengaruhi oleh ras ulat sutera yang dipelihara, jumlah mutu dan pakan yang diberikan, lingkungan pemeliharaan dan cara pemeliharaan ulat sutera.

\section{Karakteristik Kokon}

Hasil uji pada Tabel 4 menunjukkan adanya perbedaan yang sangat nyata pada taraf nyata $5 \%$ dari panjang kokon dan lebar kokon antara bibit $\mathrm{P}_{1}$ dan bibit $P_{2}$, di mana panjang rata-rata kokon bibit $P_{2}$ sebesar $31,40 \mathrm{~mm}$, panjang rata-rata kokon bibit $P_{1}$ sebesar $34,68 \mathrm{~mm}$, lebar rata-rata kokon bibit $P_{2}$ sebesar $16,47 \mathrm{~mm}$, dan lebar rata-rata kokon bibit $P_{1}$ sebesar 19,53 mm (Gambar 1).

Menurut Samsiyah dan Kusumaputra (1979), besar kecilnya ukuran kokon tergantung dari jenis ulat, suhu dan kelembaban, mutu, banyaknya daun murbei yang dimakan dan lain-lain. Menurut Tazima (1978), nilai ekonomi kokon yang tidak kalah pentingnya adalah bentuk, ukuran dan teksturnya, yang sangat ditentukan oleh perilaku ulat pada saat menjalin kokonnya.

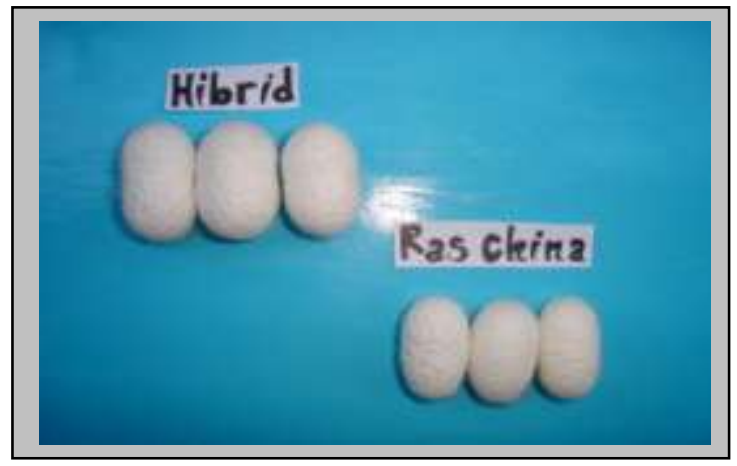

Figure 1. The coccons of $P_{1}$ and $P_{2}$ seeds

Karakteristik kokon dari kedua bibit ulat sutera pada pengamatan terhadap warna kokon, bentuk kokon, tekstur kokon, dan tingkat kekerasan kokon dapat dilihat pada Tabel 5.

Hasil pengamatan pada Tabel 5 menunjukkan bahwa kedua bibit ulat sutera memiliki warna kokon yang sama yaitu putih, di mana bibit $P_{2}$ memiliki bentuk kokon yang lonjong dengan tekstur halus sedangkan bibit $\mathrm{P}_{1}$ memiliki bentuk kokon yang lonjong sedikit berlekuk dengan tekstur kasar.

Tingkat kekerasan kokon dari bibit $\mathrm{P}_{2}$ lebih tinggi dibandingkan dengan bibit $\mathrm{P}_{1}$, di mana Samsiyah dan Kusumaputra (1979) menyatakan bahwa kokon yang memiliki tingkat kekerasan yang rendah (lembek) tidak baik digunakan sebagai bahan pemintalan sutera dan keadaan tersebut dipengaruhi oleh jenis bibit, keadaan pemeliharaan, dan pengokonan ulat.

\section{Karakteristik Ulat}

Karakteristik ulat dari kedua bibit ulat sutera dapat dilihat pada pengamatan selintas terhadap warna ulat, panjang ulat instar $\mathrm{V}$, dan tanda khas yang terdapat pada masing-masing bibit (Tabel 6).

Tabel 5. Color, shape, texture and hardness of coccons of $P_{1}$ and $P_{2}$

\begin{tabular}{cclcc}
\hline Perlakuan & Warna Kokon & Bentuk Kokon & Tekstur Kokon & Kekerasan Kokon \\
\hline Bibit $\mathrm{P}_{1}$ & Puth & Lonjong sedikit & Kasar & Agak keras \\
Bibit $\mathrm{P}_{2}$ & Perlekuk & & Halus & Sangat keras \\
\hline
\end{tabular}


Table 6. Color, lenght and mark of larva stage V of $P 1$ and $P_{2}$

\begin{tabular}{llc}
\hline \multicolumn{1}{c}{ Perlakuan } & \multicolumn{1}{c}{ Warna dan Corak Tubuh Ulat } & Rata-rata Panjang Ulat Instar V (cm) \\
\hline Bibit $\mathrm{P}_{1}$ & $\begin{array}{l}\text { Puth, bintik ("crescents") agak jelas } \\
\text { bercak mata agak jelas }\end{array}$ & 7,0 \\
Bibit $\mathrm{P}_{2}$ & Puth, polos & 6,5 \\
\hline
\end{tabular}

Table 7. Feeding, moulting, and spinning stadia of $P_{1}$ and $P_{2}$

\begin{tabular}{|c|c|c|c|c|c|c|}
\hline \multirow[b]{2}{*}{ Instar } & \multicolumn{3}{|c|}{ Bibit $P_{1}$} & \multicolumn{3}{|c|}{ Bibit Hibrid $\mathrm{P}_{2}$} \\
\hline & $\begin{array}{l}\text { Stadia Makan } \\
\text { (Hari) }\end{array}$ & $\begin{array}{c}\text { Moulting } \\
\text { (Hari) }\end{array}$ & $\begin{array}{c}\text { Stadia Larva } \\
\text { (Hari) }\end{array}$ & $\begin{array}{c}\text { Stadia Makan } \\
\text { (Hari) }\end{array}$ & $\begin{array}{l}\text { Moulting } \\
\text { (Hari) }\end{array}$ & $\begin{array}{c}\text { Stadia Larva } \\
\text { (Hari) }\end{array}$ \\
\hline 1 & 2,5 & 0,5 & 3,0 & 2,5 & 0,5 & 3,0 \\
\hline$\|$ & 3,0 & 1,0 & 4,0 & 2,5 & 1,0 & 3,5 \\
\hline III & 3,0 & 1,0 & 4,0 & 2,5 & 1,0 & 3,5 \\
\hline IV & 3,0 & 1,5 & 4,5 & 3,0 & 1,5 & 4,5 \\
\hline \multirow[t]{2}{*}{ V } & 7,5 & - & 7,5 & 6,5 & - & 6,5 \\
\hline & & Total & 23 & & Total & 21 \\
\hline
\end{tabular}

Hasil pengamatan pada Tabel 6 menunjukkan bahwa, terdapat perbedaan karakteristik ulat antara kedua bibit ulat sutera tersebut. Ulat dari bibit $P_{2}$ memiliki warna tubuh yang putih polos tanpa corak dan tanda yang khas dengan ukuran panjang tubuh ulat instar $V$ rata-rata $6,5 \mathrm{~cm}$ (Gambar 2). Sedangkan bibit $P_{1}$ memiliki warna tubuh yang putih dengan bintik (crescents) jelas pada dorsal abdomen segmen kedua dan bercak seperti mata (eye spots) pada thorax segmen kedua di tubuhnya, ukuran tubuh ulat instar V lebih besar dari bibit China dengan rata-rata $7 \mathrm{~cm}$ (Gambar 3), di mana pada bibit P1 ini terdapat tanda yang khas di tubuhnya yaitu terdapat tanda hitam di bagian thorax.

Menurut Sampe, dkk. (1989), persilangan antara polos dan bintik akan menghasilkan corak tubuh yang bintik karena alel $\left({ }^{+} p\right)$ lebih dominan dari polos (p). Tazima (1978) menjelaskan bahwa warna dan corak larva ulat sutera ditentukan oleh selain faktor genetik juga karena distribusi pigmennya dalam sel hypodermal dan epikutikula.

\section{Perkembangan Larva}

Siklus hidup ulat dari kedua bibit ulat sutera dapat dilihat pada pengamatan terhadap lamanya waktu makan (stadia makan), moulting, dan mengokon pada masing-masing bibit (Tabel 7).

Hasil pengamatan pada Tabel 7 menunjukkan bahwa terdapat perbedaan siklus hidup dari kedua bibit ulat sutera, di mana bibit $\mathrm{P}_{2}$ memiliki siklus hidup ulat (lama pemeliharaan) yang lebih pendek dibandingkan dengan bibit $P_{1}$. Adanya perbedaan siklus hidup ulat dari kedua bibit tersebut dipengaruhi oleh ras ulat sutera yang dipelihara.
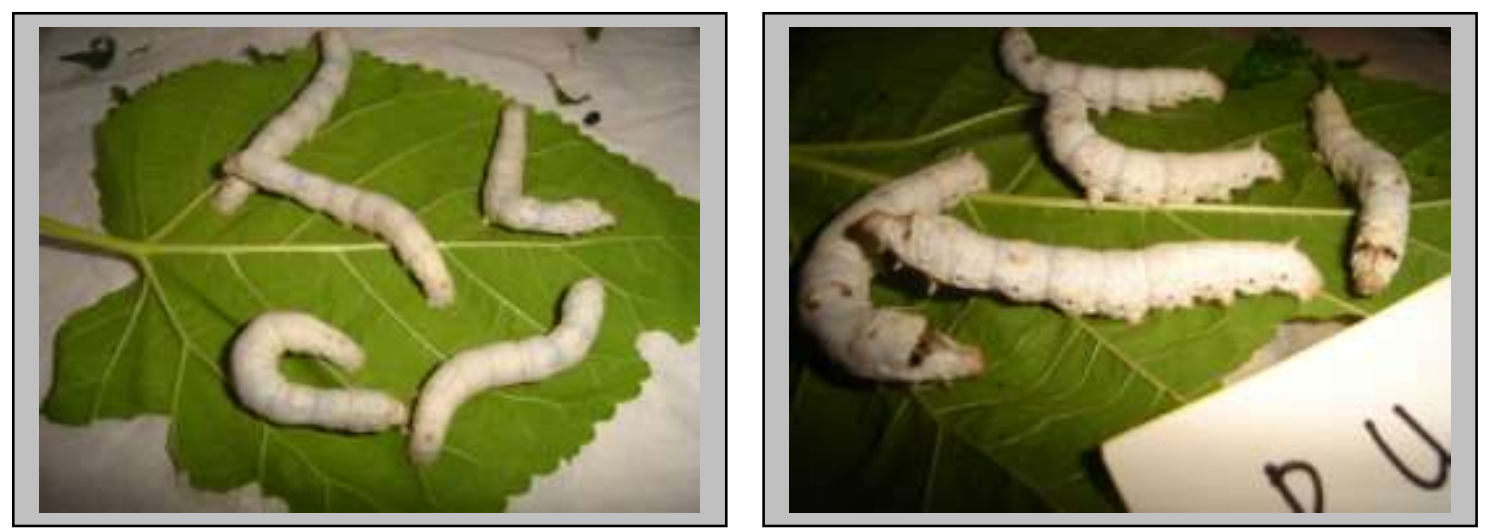

Figure 2. Motif of larva stage $V$ of $P_{1}$ (right) and $P_{2}$ (left) 


\section{KESIMPULAN}

1. Daya tetas telur antara bibit $P_{1}$ dan bibit $P_{2}$ relatif sama, sedangkan daya tahan hidup ulat kecil dan ulat besar bibit $P_{2}$ lebih tinggi dari bibit $P_{1}$, dan persentase kokon cacat bibit $P_{2}$ lebih rendah dari $P_{1}$.

2. Berat kokon segar bibit $P_{1}$ lebih tinggi dari bibit $P_{2}$, sedangkan berat kokon tanpa pupa dan persentase kulit kokon antara bibit $P_{2}$ dan bibit $\mathrm{P}_{1}$ relatif sama.

3. Panjang dan lebar kokon bibit $\mathrm{P}_{1}$ lebih besar dari bibit $\mathrm{P}_{2}$.

4. Warna kokon, bentuk kokon, tekstur kokon, dan tingkat kekerasan kokon menunjukkan adanya perbedaan dari kedua bibit.

5. Perkembangan larva bibit $P_{2}$ lebih singkat dari bibit $\mathrm{P}_{1}$.

6. Daya tahan dan kualitas kokon ulat sutera (Bombyx mori $\mathrm{L}$ ) dari bibit $\mathrm{P}_{2}$ lebih baik dibanding dengan bibit $P_{1}$.

\section{DAFTAR PUSTAKA}

Arif, 1994. Studi Mutu Kokon dan Serat Sutera dari Beberapa Sumber Bibit. Skripsi Jurusan Kehutanan Fakultas Pertanian dan Kehutanan Universitas Hasanuddin. Makassar (Tidak Dipublikasikan).

Atmosoedarjo, S., J. Kartasubrata, M. Kaomini, W. Saleh, W. Moerdoko, Pramoedibyo dan S. Ranoeprawiro. 2000. Sutera Alam Indonesia. Yayasan Sarana Wana Jaya. Jakarta.

Balai Persuteraan Alam (BPA). 1992. Kualitas dan Kuantitas Produksi Bibit Induk Ulat Sutera (Bombyx mori L.) sebagai Bahan Persilangan. BPA, Bili-Bili. Ujung Pandang.

Departemen Kehutanan. 2001. Petunjuk Praktis Pengujian dan Klasifikasi Mutu Kokon. Departemen Kehutanan, Direktorat Jenderal dan Perhutanan Sosial. Jakarta.

Higashi, Y. 1971. The Record of Silkworm Rearing in the First and Second Rearing Techniques.
Bulletin of the Thai Sericultural Research and Training Centre, No.1 July. Overseas Technical Cooperation Agency. Tokyo. Japan.

Jurnal Sulsel, 2004. Produksi Sutera Sulsel Semakin Menurun. Http://www.yahoo.com. [11 September 2007].

Katsumata, F. 1964. Petunjuk Sederhana bagi Pemeliharaan Ulat Sutera. Tokyo. Japan.

Narasimhanna. 1998. Manual on Silkworm Egg Production. National Silkworm Seed Project. Bingalore, India.

Nuraeni, S. 1993. Kuantitas dan Kualitas Produksi F1 Ulat Sutera Persilangan antara Ras Rusia dan China, Skripsi Jurusan Hama dan Penyakit, Fakultas Pertanian, Universitas Hasanuddin. Ujung Pandang.

Nurjannah, 2002. Perbandingan Kualitas Kokon Produksi Perum Perhutani dengan Kokon Produksi Petani di Kabupaten Soppeng. Skripsi Jurusan Kehutanan, Fakultas Pertanian dan Kehutanan, Universitas Hasanuddin. Makassar (Tidak dipublikasikan).

Samsiyah dan Kusumaputera. 979. Pedoman Pengolahan Kokon dan Benang Sutera. Proyek Pembinaan Persuteraan Alam. Sulawesi Selatan.

Suryani, A. 1993. Perbandingan Produksi Ulat Sutera Keturunanan Pertama (F1) dari Hasil Persilangan Ras Jepang dan Ras China di Bili-Bili Kabupaten Gowa. Skripsi Jurusan Kehutanan. Fakultas Pertanian dan Kehutanan, Universitas Hasanuddin. Makassar (Tidak dipublikasikan).

Tazima, Y. 1978. The Silkworm: an Important Laboratory Tool. Kodarsha Ltd. Tokyo. Japan.

Omura, 1980. Silkworm Rearing Technics in Tropics. Japan Internasional Coorperation Agency, Tokyo, Japan.

Diterima : 19 November 2007

Sitti Nuraeni

Fakultas Pertanian, Universitas Haluoleo

Kampus Bumi Tri Dharma, Kendari, Indonesia

E_mail: enychiko@yahoo.com 


\section{Beta Putranto}

Lab. Keteknikan dan Diversifikasi Hasil Hutan

Fakultas Kehutanan Universitas Hasanuddin

Jl. Perintis Kemerdekaan Km 10 Tamalanrea, Makassar 90245

Telp/Fax. (0411) 589592 